\title{
Plant Growth-Promoting Activities and Molecular Characterization of Rhizobacterial Strains Isolated From Medicinal and Aromatic Plants
}

\author{
D. Malleswari ${ }^{1}$, G. Bagyanarayana ${ }^{2}$ \\ Department of Botany, Osmania University, Hyderabad-500 007, A. P., India
}

\begin{abstract}
Rhizosphere bacteria are known to influence plant growth by direct and indirect mechanisms. Development of an effective plant growth promoting rhizobacteria $(P G P R)$ inoculant necessitates the presence of a diverse set of traits that can help its colonization of the rhizosphere and survival under varying environmental conditions. In the present study, a total of 219 bacterial strains isolated from the rhizosphere of different medicinal and aromatic plants collected from different locations of Andhra Pradesh (India) were initially screened for their PGP activities. From the 219 isolates four bacterial strains were selected and tested for in vitro specific plant growth promotion activities such as ammonia production, IAA production, phosphate solubilization, HCN production and antifungal activity. These four isolates showed maximum plant growth promoting activities and further they were identified on the basis of colony morphology, gram staining and biochemical tests. These PGPR isolates were characterized through $16 S$ rRNA gene sequencing which led to their identification as Pantoea sp. (Cf 7), Bacillus sp. (Cf 60) and Pseudomonas sp. (Tel, Av 30) respectively. Seed germination test was conducted by employing these strains under laboratory conditions on sorghum, maize and green gram seeds to investigate the effect of PGPR on the growth of seedlings. These PGPR isolates induced production of plant growth hormones (indole acetic acid), phosphate solubilization and ammonia production resulting in enhanced plant growth. Most of the isolates resulted in a significant increase in \% of seed germination, shoot length, root length and vigor index of sorghum, maize and green gram seedlings. Therefore, the present study suggests that these PGPR isolates ( $\mathrm{Cf}$ 7, Cf 60, Tel, Av 30) may be used as biofertilizers to enhance the growth and productivity of commercially important medicinal and aromatic plants. Key Words: PGPR, PGP activities, medicinal and aromatic plants
\end{abstract}

\section{Introduction}

Microorganisms has vital role in agriculture to promote the exchange of plant nutrients and reduce application of chemical fertilizers as much as possible. Plant growth promoting rhizobacteria (PGPR) are able to exert a positive effect leading to plant growth. Beneficial plant-microbe interactions in the rhizosphere can influence plant vigor and soil fertility [1]. These beneficial effects of PGPR have direct or indirect performance on plants. Direct promotion of growth by PGPR including production of metabolites that enhances plant growth such as auxins [2], cytokinins, gibberellins and through solubilization of phosphate minerals etc. [3]. Indirect growth promotion occurs via the removal of pathogens by the production of secondary metabolites such as hydrogen cyanide and siderophores etc. [4].

The application of plant growth promoting rhizobacteria (PGPR) as crop inoculants for biofertilization, phytostimulation and biocontrol would be an attractive alternative to decrease the use of chemical fertilizers which also effect environmental pollution due to indiscriminate application [5]. Pantoea, Bacillus, Pseudomonas etc. are widespread species of in agricultural soils and has many traits that make them well-matched as PGPR.

Development of an effective plant growth promoting rhizobacteria (PGPR) inoculant necessitates the presence of a diverse set of traits that can help its colonization of the rhizosphere and survival under varying environmental conditions. Therefore, in the present investigation, our attempts were directed towards the selection of strains exhibiting the highest number of traits associated with the PGP ability under in vitro conditions. The objectives of this study were isolation, screening and biochemical characterization of PGPR isolates and evaluate their beneficial effects on plant growth promoting properties. 


\subsection{Soil sampling}

\section{Materials and Methods}

Soil samples were collected from the rhizosphere of some medicinal and aromatic plants i.e. Coleus forskohlii, Withania somnifera, Ocimum sanctum, Andrographis paniculata, Mentha spicata, Aloe vera, Tagetes erecta, Artemisia vulgaris, Acorus calamus and Mimosa pudica growing in different locations of Andhra Pradesh, India., and designated as location A (Botanical garden, O.U, Hyderabad), location B (CIMAP, Hyderabad), location C (AICRP on MAP \& Betel Vine, West Godavari \& Hyderabad), location D (ANGRAU, Hyderabad), location E (SILPA Agro farms Pvt. Ltd, Medak). Intact root system was dug out and the rhizospheric soil samples were carefully taken in plastic bags and stored at $4^{\circ} \mathrm{C}$. A total of 25 soil samples were collected for the isolation of rhizosphere bacterial isolates.

\subsection{Isolation and preliminary screening of the bacterial isolates}

The plant growth promoting rhizobacteria (PGPR) were isolated from the rhizospheric soil samples by serial dilution plate technique. Appropriate dilution was spread on nutrient and king's B agar plates. Plates were incubated at $30^{\circ} \mathrm{C}$ for $24-48 \mathrm{~h}$. Colonies were picked from these plates and maintained as pure cultures in respective medias with periodic transfer to fresh media and stocked for further use. All the isolates were maintained at $4^{\circ} \mathrm{C}$ in equal volumes of nutrient broth and $30 \%$ glycerol.

All the 219 bacterial isolates were screened for their growth promoting activities like ammonia production, indole acetic acid (IAA) production, phosphate solubilization, HCN production, antifungal activity and hydrolytic enzyme production such as cellulases, chitinases, proteases and lipases.

\subsection{Detection of plant growth promoting (PGP) traits of the selected isolates}

\subsubsection{Ammonia $\left(\mathrm{NH}_{3}\right)$ and indole acetic acid (IAA) production}

Ammonia production was detected by adding $1 \mathrm{ml}$ Nessler's reagent to a $72 \mathrm{~h}$ old culture grown in peptone broth (Peptone- 10g, NaCl-5g, Distilled water-1lit) and recorded the presence of the deep yellow to brown colour [6].

Production of indole acetic acid (IAA) in the bacterial isolates was estimated by inoculation of bacterial suspension into Luria Bertani (LB) broth containing tryptophan. The cultures were kept at $28 \pm 2{ }^{\circ} \mathrm{C}$ for $48 \mathrm{~h}$ and then centrifuged at $10,000 \mathrm{rpm}$ for $15 \mathrm{~min}$. $2 \mathrm{ml}$ of supernatant was mixed with $4 \mathrm{ml}$ Salkowski reagent $(1 \mathrm{ml}$ of $0.5 \mathrm{M} \mathrm{FeCl}_{3}$ in $50 \mathrm{ml}$ of $35 \% \mathrm{HClO}_{4}$ ) and absorbance of the resultant pink color was read after $30 \mathrm{~min}$ at $530 \mathrm{~nm}$ in calorimeter. Appearance of pink color in test tubes indicated IAA production. The IAA production was calculated from the regression equation of standard curve and the result was expressed as $\mu \mathrm{g} / \mathrm{ml}$ over control [7].

\subsubsection{HCN production and phosphate solubilization}

Hydrogen cyanide ( $\mathrm{HCN}$ ) production was evaluated by streaking the bacterial isolates on King's B agar medium amended with glycine. Whatman No.1 filter paper soaked in picric acid $(0.05 \%$ solution in $2 \%$ sodium carbonate) was placed in the lid of each Petri plate. The plates were then sealed air-tight with Parafilm and incubated at $30^{\circ} \mathrm{C}$ for $48 \mathrm{~h}$. A colour change of the filter paper from deep yellow to reddish-brown colour was considered as an indication of HCN production [8].

A qualitative assay for $\mathrm{P}$ solubilization was performed in Pikovskaya agar medium containing tricalcium phosphate (Glucose 10.0, $\mathrm{Ca}_{3}\left(\mathrm{PO}_{4}\right)_{2} 5.0,\left(\mathrm{NH}_{4}\right)_{2} \mathrm{SO}_{4} 0.5, \mathrm{KCl} 0.2, \mathrm{MgSO}_{4} .7 \mathrm{H}_{2} \mathrm{O} 0.1, \mathrm{MnSO}_{4} 0.002$, $\mathrm{FeSO}_{4}$ 0.002, Yeast Extract 0.5, Agar 16.0, Distilled water 1lit). Bacterial culture was streaked on the medium and incubated at $30^{\circ} \mathrm{C}$ for $48 \mathrm{~h}$. The presence of a clear halo zone around the culture indicates the $\mathrm{P}$ solubilization capacity of the isolate [9].

\subsubsection{Antifungal activity}

The antifungal activity of the bacteria was assessed against the test pathogen (Macrophomina phaseolina) by dual culture technique [10] on potato dextrose agar (PDA) medium. The diameter of the zone of inhibition was measured after $72 \mathrm{~h}$. The level of inhibition was calculated by subtracting the distance $(\mathrm{mm})$ of fungal growth in the direction of an antagonist from the fungal radius. The percent inhibition was calculated using the formula:

$$
\% \text { inhibition }=(\mathrm{R}-\mathrm{r}) / \mathrm{R} \times 100
$$

Where ' $\mathrm{r}$ ' is radial growth of the fungal colony opposite the bacterial colony and, $\mathrm{R}$ is the radial growth of the pathogen in control plate.

\subsection{Evaluation of plant growth promoting ability of bacterial isolates}

The selected rhizobacterial isolates were bioassayed for their ability to promote or inhibit seedling growth using the seed germination method described by Elliot and Lynch [11] with a few modifications. Seeds were surface sterilized with $0.1 \% \mathrm{HgCl}_{2}$ for $3 \mathrm{~min}$ and washed with distilled water for $4-5$ times. The seeds were 
soaked for 20-30 min in $48 \mathrm{~h}$ old bacterial broth cultures containing at least $10^{-6}$ cells $/ \mathrm{ml}$. The seeds were kept on sterilized filter paper (in petri plates) and incubated at $30^{\circ} \mathrm{C}$. From 2 to 8 days, $\%$ of seed germination, root and shoot lengths were recorded. The Vigor Index was calculated as:

VI $(\%)=($ mean root length + mean shoot length $) \times$ germination $\%$.

\subsection{Screening of bacterial isolates for hydrolytic enzyme production}

The selected isolates were screened for their hydrolytic enzyme production like chitinase, cellulase, protease, lipase and amylase activities.

\subsubsection{Production of chitinase}

The qualitative assay for chitin production was performed on colloidal chitin medium (Colloidal chitin 4.0, $\mathrm{K}_{2} \mathrm{HPO}_{4}$ 0.7, $\mathrm{KH}_{2} \mathrm{PO}_{4}$ 0.3, $\mathrm{MgSO}_{4}$ 0.5, $\mathrm{FeSO}_{4}$ 0.01, $\mathrm{ZnSO}_{4}$ 0.001, $\mathrm{MnCl}_{2}$ 0.001, Agar 15.0, Distilled water $1000 \mathrm{ml}$ ) for 4 days at $28 \pm 2{ }^{\circ} \mathrm{C}$. Clearance halos around and beneath the colony were observed around the bacterial colonies indicating the enzymatic degradation of chitin.

\subsubsection{Production of caseinase (protease)}

The qualitative assay for protease production was performed on sterile skim milk agar plates (Panc. digest of casein 5.0, Yeast extract 2.5, Glucose 1.0, Agar 15.0, Distilled water 1000ml, Skim milk 7\% was added as inducer). Isolates were spot inoculated and followed by incubation at $30^{\circ} \mathrm{C}$ and zone of clearance around the colony indicating the enzymatic degradation of protease.

\subsubsection{Production of lipase}

Bacteria were grown on nutrient agar amended with egg yolk. After $48 \mathrm{~h}$ of incubation the agar medium was flooded with saturated aqueous solution of copper sulphate $\left(\mathrm{CuSo}_{4}\right)$ and kept for $10-15 \mathrm{~min}$. The excess reagent was poured off. Formation of greenish blue colour zones around the colony indicated the production of lipase.

\subsubsection{Production of amylase (starch hydrolysis)}

The bacterial isolates were spot inoculated on starch agar (Beef extract 3.0, Peptone 5.0, Soluble Starch 2.0, Agar 15.0, Distilled water 1lit) medium plates and incubated at $30^{\circ} \mathrm{C}$ for $48 \mathrm{~h}$. At the end of incubation period, the plates were flooded with iodine solution, kept for a minute and then poured off. Iodine reacts with starch to form a blue colour compound. This blue colour fades rapidly. Hence the colour less zone surrounding colonies indicates the production of amylase.

\subsubsection{Catalase activity}

The Selected PGPR isolates were streaked on trypticase soya agar medium (Trypticase 15, Phytone 5.0, $\mathrm{NaCl} 5.0$, Agar 15.0, Distilled water 1 lit) and incubated for $48 \mathrm{~h}$ at $30^{\circ} \mathrm{C}$, while holding the inoculated plate, 3-4 drops of hydrogen peroxide $\left(\mathrm{H}_{2} \mathrm{O}_{2}\right)$ was allowed to flow over the growth of each plate. Observations were made for the production of gas bubbles within a minute indicating the production of catalase activity.

\subsection{Morphological and biochemical characterization of isolates}

The selected bacterial isolates were examined for their morphological features. The morphological characteristics were examined on their respective agar plates. The pure cultures from the slants were plated on the agar plates. After the growth of colonies morphological characters of the colonies like the colour, shape, size, surface and gram staining etc. were recorded.

The biochemical characterization of selected PGPR strains was essentially done by using KB002 Hi Assorted TM Biochemical test kit (HiMedia) and other biochemical tests such as carbohydrate fermentation, IMViC tests, gelatin liquefaction etc. are done by using standard procedures.

\subsection{Antibiotic assay}

The selected bacterial isolates were tested for their antibiotic activity (Nalidixic acid, Penicillin-G, Chloramphenicol, Ampicillin, Nitrofurazone, Novobiocin, Neomycin). Bacterial cultures were inoculated aseptically on nutrient agar plate completely so as to make a lawn. The antibiotic disc carefully taken with a sterilized forcep and placed over the agar plate. Plates were Incubated for 18 to $24 \mathrm{~h}$ at $37^{\circ} \mathrm{C}$. Observations were recorded by measuring the zone of inhibition around the antibiotic discs.

\subsection{S rRNA sequencing of PGPR isolates}

The 16S rRNA sequencing was performed by a sequencing service (Macrogen, South Korea). Selected bacterial 16S rRNA was amplified in full length by PCR using two pairs of primers, 518F (CCAg- 
CAgCCgCggTAATACg) and 800R (TACCAggg-TATCTAATCC) and 27F (AgAgTTTgATCMT-GGCTCAg) and 1492R (TACggYTACCTTgTTA-CgACTT). To evaluate the phylogenetic analysis of 16S rRNA sequences, the resulting sequences were compared with the known sequences using the BLAST function of GeneBank in the National Center Biotechnology information (http://www.ncbi.nlm.nih.gov). Multiple sequence alignments and consensus sequences were computed using the program CLUSTALW programmed at European Bioinformatics (EBI) site (http://www.ebi.eic.uk/clustalw). The resulted BLAST hits were analyzed for evolutionary significance using tree view programme. Evolution trees for the data sets were inferred from the neighbor-joining methods by using the neighbor-joining program of Molecular Evolutionary Genetic Analysis software version 4 (MEGA 4.0) The gene sequences were also submitted to EMBL and accession numbers were assigned.

\subsection{Selection of bacterial isolates}

\section{Results and Discussion}

Microbial diversity in soil is considered important for maintaining the sustainability of agriculture production systems. The quantity and activity of microorganisms are determining factor of the productivity of any kind of soil [12]. A total of 219 rhizobacterial strains were isolated from the rhizosphere of medicinal, aromatic plants i.e. Coleus forskohlii, Withania somnifera, Ocimum sanctum, Andrographis paniculata, Mentha spicata, Aloe vera, Tagetes erecta, Artemisia vulgaris, Acorus calamus and Mimosa pudica growing at different locations in Andhra Pradesh, India and they are screened on the basis of PGP activities and the seed germination assay. Four potential bacterial isolates were selected for further study which performed multiple PGP characteristics exhibiting enhanced the root, shoot length and vigor index of seedlings significantly compared to untreated controls.

\subsection{PGP traits of the selected isolates}

Plant rhizosphere is known to be preferred ecological niche for soil microorganisms due to nutrient rich availability. Plant growth promoting activities such as IAA production, ammonia, phosphate solubilization etc. are the characteristics of plant growth promoting rhizobacteria (PGPR). The isolates in this study presented several enviable features for PGPR, and multiple action mechanisms which suggest their potential for growth promotion. In the present study all the four selected strains (Cf 7, Te 1, Av 30 and Cf 60) were positive for plant growth promoting hormones ammonia and indole acetic acid (IAA) production. The amount of IAA produced varied from $20 \mu \mathrm{g} / \mathrm{ml}$ to $60 \mu \mathrm{g} / \mathrm{ml}$, with Av 30 producing maximum amount of $60 \mu \mathrm{g} / \mathrm{ml}$ followed by Te $1(46.6 \mu \mathrm{g} / \mathrm{ml})$, Cf $7(25 \mu \mathrm{g} / \mathrm{ml})$ and the least amount was produced by the isolate Cf $60(15 \mu \mathrm{g} / \mathrm{ml})$ (Table 1$)$. Similar observations for IAA production have been reported by other researchers. Production of IAA by rhizobacterial isolates is also detected by other workers in Bacillus, Pseudomonas and other rhizobacterial isolates $[13,14,15]$.

Soil is a storehouse of several forms of phosphate, including inorganic and organic phosphate, mineralization of most organic phosphorous compounds is carried out by means of phosphatase enzymes. In our study, two isolates Cf 7 and Te 1 showed phosphate solubilizing activity and remaining 2 failed to show such activity. Te 1 exhibited maximum $\mathrm{HCN}$ production. $\mathrm{HCN}$ are known to be intricately related to antifungal activity. The production of HCN in excess may play a critical role in the control of fungal diseases [16]. Rest of the three failed to produce $\mathrm{HCN}$.

Antagonistic microorganisms are a potential non-chemical means of plant disease control. Many strains of Bacillus have been shown to be potential biocontrol agents against fungal pathogens [17]. In the present study, Bacillus subtilis (Cf 60) was showing plant growth promoting and bioprotecting activity which was originally isolated from Coleus rhizosphere. Bacterial isolate Cf 60 showed maximum growth inhibition of Macrophomina phaseolina (52.22\%) in dual culture plate. All the selected strains were strong IAA, Ammonia and Catalase producers, thus indicating their potential for plant growth promoting effects.

\subsection{Production of hydrolytic enzymes}

The bacterial strains that produce different hydrolytic enzymes were effected antagonistically to soil fungi $[18,19,20]$. Therefore, the collection of bacterial antagonists retrieved in this study, were phenotypically characterized in vitro to explore possible mechanisms of antagonistic activity based on protease, chitinase and lipase production, while from these results it can be revealed that the production of these enzymes would be the most prominent traits among the antagonists. Four potential strains which are showing multiple PGP activities were tested for these activities. Cf 60, Te 1 and AV 30 were showing protease activity, Cf 7, Cf 60 and Av 30 were positive for lipase activity, Amylase and chitinase activity were observed only in Bacillus subtilis (Cf 60). Production of catalase was exhibited by all the isolates of rhizobacteria. Catalase activity was detected in all the bacterial strains that may be potentially very advantageous (Table 1). 


\subsection{Evaluation of plant growth promoting ability of bacterial isolates}

Selected isolates could exhibit more than two or three PGP traits, which may promote plant growth directly or indirectly or synergistically. Similar to our findings of multiple PGP activities among PGPR have been reported by some other workers [21,22]. In the present study PGPR seed inoculation significantly enhanced seed germination and seedling vigor of sorghum, maize and green gram. The highest response for seed germination and vigor index was observed with isolate Av $30(93.3 \%, 99)$ in sorghum, with Cf $7(93.3 \%$, 7034) in maize and with Te1 in green gram $(93.3 \%, 1250)$. The relative germination was found to be increased up to $200 \%$ with the Av 30 in sorghum, 233\% with $\mathrm{Cf} 7$ in maize, and $165 \%$ with Te 1 in green gram recorded over untreated controls (Fig. 1,2).

\subsection{Morphological and biochemical characterization of the selected isolates}

All the isolates were motile rods, three isolates ( $\mathrm{Cf} 7, \mathrm{Te} 1, \mathrm{Av} 30$ ) were gram-negative and $\mathrm{Cf} 60$ is Gram positive. The isolate $\mathrm{Cf} 7$ produced large, rough, pale yellow mucoid colonies with raised entire edges and elevated centre on King'B agar. The isolate Cf 60 produced large, smooth, white colonies with flat edges and elevated centre on nutrient agar. The isolate Te 1 produced small, smooth, yellow mucoid colonies with and raised centre on King'B agar. A characteristic fluorescent green pigmentation was observed under UV light. Av 30 produced large yellow mucoid colonies with flat entire edges on King’B agar.

All the four isolates were positive for citrate utilization except Av 30; three isolates were positive for lysine utilization and $\mathrm{Cf} 7$ were negative for lysine utilization; Av 30, Te 1 were positive for indole remaining are negative (Cf 7, Cf 60); 3 strains were positive for arabinose, lactose except $\mathrm{Cf} 60$; only Av 30 were found positive for ornithine utilization remaining were negative; None of the isolates were positive for urease, phenylalanine deamination, nitrate, $\mathrm{H}_{2} \mathrm{~S}$ production, voges proskaur reaction. Te $1, \mathrm{Av} 30$ were positive for glucose, gelatinase. All are negative for adonitol except Av 30. All the strains were positive for sorbitol and methyl red test which aided in designating them as belonging to Pantoea sp., Pseudomonas sp. and Bacillus sp. (Table 2).

\subsection{Antibiotic assay}

Resistance of PGPR to several antibiotics might have an ecological advantage of survival in the rhizosphere when they are introduced as inoculum. The selected rhizobacterial isolates showed distinct zone of inhibition against some antibiotics i.e. nalidixic acid, penicillin-g, chloramphenicol, ampicillin, nitrofurazone, novobiocin and neomycin. Cf 7 was more sensitive to nalidixic acid $(1.7 \mathrm{~mm})$, Te 1 showed zone of $6 \mathrm{~mm}$ only against nalidixic acid, Av 30 is more sensitive to chloramphenicol and $\mathrm{Cf} 60$ also sensitive to chloramphenicol and showed $1.6 \mathrm{~mm}$ zone of inhibition. Bacillus subtilis (Cf 60) is susceptible for all the antibiotics and showed good zone of inhibition, Pantoea agglomerans ( $\mathrm{Cf} 7$ ) and Pseudomonas putida (Te 1) was more sensitive to nalidixic acid (17 mm, $6 \mathrm{~mm}$ ), Pseudomonas spp. (Av 30) more sensitive to chloramphenicol (Table 3).

\subsection{Molecular characterization of the selected isolates}

Molecular tools have great potential in identifying and tracing the phylogeny of the organisms. PCR amplification of variable regions of the genes encoding 16S rRNA by using primers homologous to conserved regions of the gene (Fig. 3). In the present study the sequenced PCR products of bacterial isolates were matched with the available sequences in the GenBank database. On the basis of 16S rDNA sequencing data, bacterial isolates Cf 7, Cf 60 and Te 1 showed 99\% similarity with the Pantoea sp., Bacillus sp., and Pseudomonas sp. The GenBank accession numbers of the isolates HE659514 (Cf 7), HE659513 (Te 1) and HE659512 (Cf 60) respectively.

\section{Conclusion}

In conclusion, our result suggested that simultaneous screening of rhizobacteria for plant growth promoting activities is a good tool to select effective PGPR for biofertilizer development. Results suggest that PGPR are able to produce IAA, solubilize the phosphate and show antagonism towards pathogens thereby may improve the growth of plants. The prospective species could be recovered from enrichment methods, nevertheless with the potential of $16 \mathrm{~S}$ rRNA sequencing analysis, the diversity of bacteria isolated from rhizosphere soils of different aromatic and medicinal plants was shown. The use of such PGPR singly or in consortium can act as efficient bioinoculants which may be an approach to reduce the usage of chemical fertilizers and pesticides for sustainable cultivation of medicinal and aromatic plants. Further investigations like efficiency test under green house and field conditions are needed to evaluate the role of PGPR. 


\section{Acknowledgments}

The authors express their thanks to the Co-Ordinator, OU-DST-PURSE (Promotion of university research and scientific excellence) Programme, for the Financial Assistance and The Head, Department of Botany, Osmania University for the physical facilities.

\section{References}

[1]. S.G. Dastager, C.K. Deepa, and A. Pandey, Potential plant growth-promotingactivity of Serratia nematodiphila NII-0928 on black pepper (Piper nigrum L.). World Journal of Microbiology and Biotechnology, 27, 2011, 259-265.

[2]. B. Ali, A.N. Sabri, and S. Hasnain, Rhizobacterial potential to alter auxin content and growth of Vigna radiata (L.). World Journal of Microbiology and Biotechnology, 26, 2010, 1379-1384.

[3]. M.E. El-Hadad, M.I. Mustafa, S.M. Selim, A.E.A. Mahgoob, and T.S. El-Tayeb, In vitro evaluation of some bacterial isolates as biofertilizers and biocontrol agents against the second stage juveniles of Meloidogyne incognita. World Journal of Microbiology and Biotechnology, 26, 2010, 2249-2256.

[4]. H.A. Idris, N. Labuschagne, and L. Korsten, Suppression of Pythium ultimum root rot of sorghum by rhizobacterial isolates from Ethiopia and South Africa. Biological Control 45, 2010, 72-84.

[5]. B. Ali, A.N. Sabri, and S. Hasnain, Rhizobacterial potential to alter auxin content and growth of Vigna radiata (L.). World Journal of Microbiology and Biotechnology, 26, 2010, 1379-1384.

[6]. A.W. Bakker and B. Schipperes, Microbial cyanide production in the rhizosphere in relation to potato yield reduction and Pseudomoas spp. mediated plant growth stimulation. Soil Biology and Biochemistry, 19, 1987, 451-457.

[7]. A.S. Gordon, and R.P. Weber, Colorimetric estimation of indole acetic acid. Plant Physiology, 26, 1951,192-195.

[8]. D.W. Dye, The inadequacy of the usual determinative tests for identification of Xanthomonas sp. New Zealand Journal of Science, 5, 1962, 393-416.

[9]. R.E. Pikovskaya, Mobilization of phosphorous in soil in connection with vital activity of some microbial species, Mikrobiologiya $17,1948,362-370$.

[10]. R. Rabindran, and P. Vidyasekaran, Development of a formulation of Pseudomonas fluorescens PfALR2 for management of rice sheath blight. Crop Protection,15, 1996, 715-721.

[11]. F. Elliot, and J.M. Lynch, Pseudomonas as a factor for the growth of winter wheat (Triticum aestivum L.). Soil Biology and Biochemistry, 16, 1984, 69-71.

[12]. C.M. Ribeiro, and E.J. Cardoso, Isolation, selection and characterization of root associated growth promoting bacteria in Bra zil Pine (Araucaria angustifolia). Microbiological Research, 167, 2011, 69-78.

[13]. P. Calvo, E.O. Orrillo, E.M. Romero, and D. Zuniga, Characterization of Bacillus isolates of potato rhizosphere from Andean soils of Peru and their potential PGPR characteristics. Brazil Journal of Microbiology, 41, 2010, 899-906.

[14]. Y. Bai, D.A. Frederic, L.S. Donald, and T.D. Brian, Isolation of plant-growth-promoting Bacillus strains from soybean root nodules. Canadian Journal of Microbiology, 48, 2002: 230-238.

[15]. E.L. Selvadurai, A.E. Brown, and J.T.G. Hamilton, Production of indole-3-acetic acid analogues by strains of Bacillus cereus in relation to their influence on seedling development. Soil Biology and Biochemistry, 23, 1991, 401-403.

[16]. E. Banchio, P.C. Bogino, J. Zygadlo, and W. Giordano, Plant growth promoting rhizobacteria improve growth and essential oil yield in Origanum majorana L. Biochemical Systematics and Ecology, 36, 2008, 766-771

[17]. Sapna Sharma, and Mohinder Kaur, Antimicrobial activities of rhizobacterial strains of Pseudomonas and Bacillus strains isolated from rhizosphere soil of carnation (Dianthus caryophyllus cv. Sunrise). Indian Journal of Microbiology, 50, 2010, 229-232.

[18]. A.J. Cattelan, P.G. Hartel, and J.J. Fuhrmann, Screening for plant growth-promoting rhizobacteria to promote early soybean growth. Soil Science Society of America Journal, 63, 1999, 1670-1680.

[19]. M.A. Flaishman, Z.A. Eyal, A. Zilberstein, C. Voisard, and D.Hass, Suppression of Septoria tritci blotch and leaf rust of wheat by recombinant cyanide producing strains of Pseudomonas putida. Molecular Plant Microbe Interactions, 9, $1996,642-645$.

[20]. D. Fravel, Role of antibiosis in the biocontrol of plant diseases. Annual Reviews of . Phytopathology, 26, 1988, 75-79.

[21]. B. Lugtenberg, T. Chin-A-Woeng, and G. Bloemberg, Antonie van Leeuwenhoek 81, 2002, 373-383.

[22]. Berg Gabriele, Zachow Christin, Lottmann Jana, Götz Monika, Costa Rodrigo, and Smalla Kornelia, Impact of plant species and site on rhizosphere-associated fungi antagonistic to Verticillium dahliae kleb. Applied Environmental Microbiology, 71(8), $2005,4203-4213$ 
Table 1 Plant Growth Promoting Characteristics and hydrolytic enzyme production of rhizobial isolates

\begin{tabular}{|l|l|l|l|l|}
\hline Activity & Cf 7 & Cf 60 & Te 1 & Av 30 \\
\hline $\mathrm{NH}_{3}$ production & ++ & ++ & +++ & +++ \\
\hline IAA production $(\mu \mathrm{g} / \mathrm{ml})$ & 25.0 & 15.0 & 46.6 & 60.0 \\
\hline HCN Production & - & - & +++ & - \\
\hline 'P' Solubilization & +++ & - & ++ & - \\
\hline Antifungal activity & - & +++ & - & - \\
\hline Chitinase & - & ++ & - & - \\
\hline Protease & - & + & + & + \\
\hline Lipase & + & + & - & + \\
\hline Amylase & - & + & - & - \\
\hline Catalase & + & + & + & + \\
\hline
\end{tabular}

$-=$ no production, $+=$ week production,$++=$ medium production,$+++=$ high production

Table 2 Morphological, Cultural and Biochemical Characteristics of PGPR Isolates

\begin{tabular}{|c|c|c|c|c|}
\hline Biochemical test & Cf 7 & Cf 60 & Te 1 & Av 30 \\
\hline Gram's Reaction & - ve & $+\mathrm{ve}$ & - ve & - ve \\
\hline Cell Shape & Rod & Rods & Rod & Rod \\
\hline Size $(\mathrm{mm})$ & 0.5 & $0.5-1.1$ & 0.5 & 0.5 \\
\hline Elevation & Raised & Flat & Raised & Flat \\
\hline Motility & Motile & Motile & Motile & Motile \\
\hline Colour & Pale Yellow & White & Yellow & Yellow \\
\hline Pigmentation & None & None & None & None \\
\hline Citrate utilization & + & + & + & - \\
\hline Lysine utilization & - & - & + & + \\
\hline Ornithine utilization & - & - & - & + \\
\hline Urease & - & - & - & - \\
\hline Phenylalanine deamination & - & - & - & - \\
\hline Nitrate & - & - & - & - \\
\hline $\mathrm{H}_{2} \mathrm{~S}$ production & - & - & - & - \\
\hline Glucose & - & - & + & + \\
\hline Adonitol & - & - & - & + \\
\hline Lactose & + & - & + & + \\
\hline Arabinose & + & - & + & + \\
\hline Sorbitol & + & + & + & + \\
\hline Indole & - & - & + & + \\
\hline Methyl red & + & + & + & + \\
\hline Voges Prokaur & - & - & - & - \\
\hline Gelatinase & - & - & + & + \\
\hline
\end{tabular}

Table 4 Antibiotic activity of selected rhizobacterial isolates

\begin{tabular}{|l|l|l|l|l|}
\hline Antibiotic & $\begin{array}{l}\text { Pantoea sp. } \\
(\mathbf{C f 7}) \\
\text { Zone of inhibition } \\
(\mathbf{m m})\end{array}$ & $\begin{array}{l}\text { Pseudomonas sp. } \\
\text { (Te 1) } \\
\text { Zone of inhibition } \\
(\mathbf{m m})\end{array}$ & $\begin{array}{l}\text { Pseudomonas sp. } \\
(\text { Av 30) } \\
\text { Zone of inhibition } \\
(\mathbf{m m})\end{array}$ & $\begin{array}{l}\text { Bacillus sp. } \\
(\mathbf{C f} \text { 60) } \\
\text { Zone of inhibition } \\
(\mathbf{m m})\end{array}$ \\
\hline Nalidixic acid & 17 & 6 & 10 & 15 \\
\hline Penicillin-G & - & - & - & 6 \\
\hline Chloramphenicol & 13 & - & 13 & 16 \\
\hline Ampicillin & - & - & - & 10 \\
\hline Nitrofurazone & 13 & - & 12 & 12 \\
\hline Novobiocin & 5 & - & 12 & 10 \\
\hline Neomycin & 6 & 3 & 5 & 6 \\
\hline Control & - & - & - & - \\
\hline
\end{tabular}




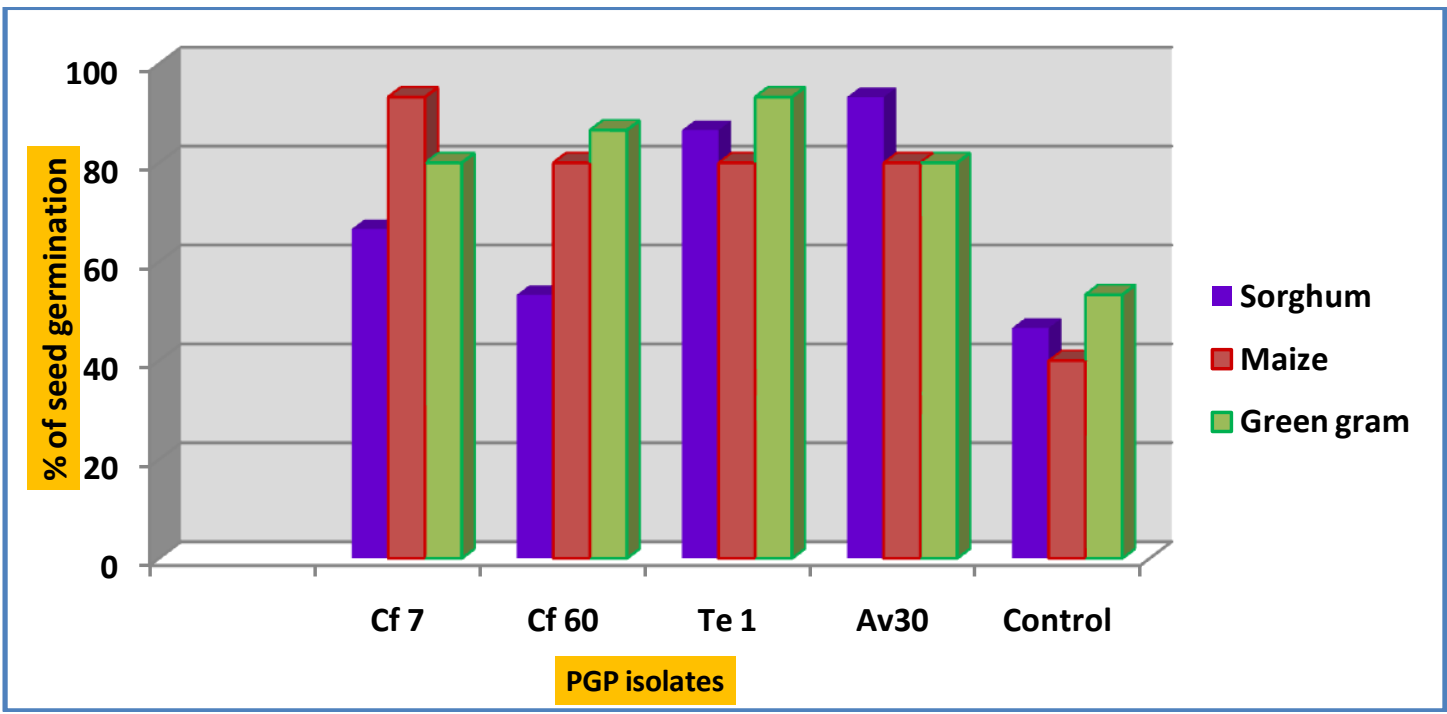

Fig. 1. Effect of PGPR isolates on seed germination of sorghum, maize and green gram seedlings

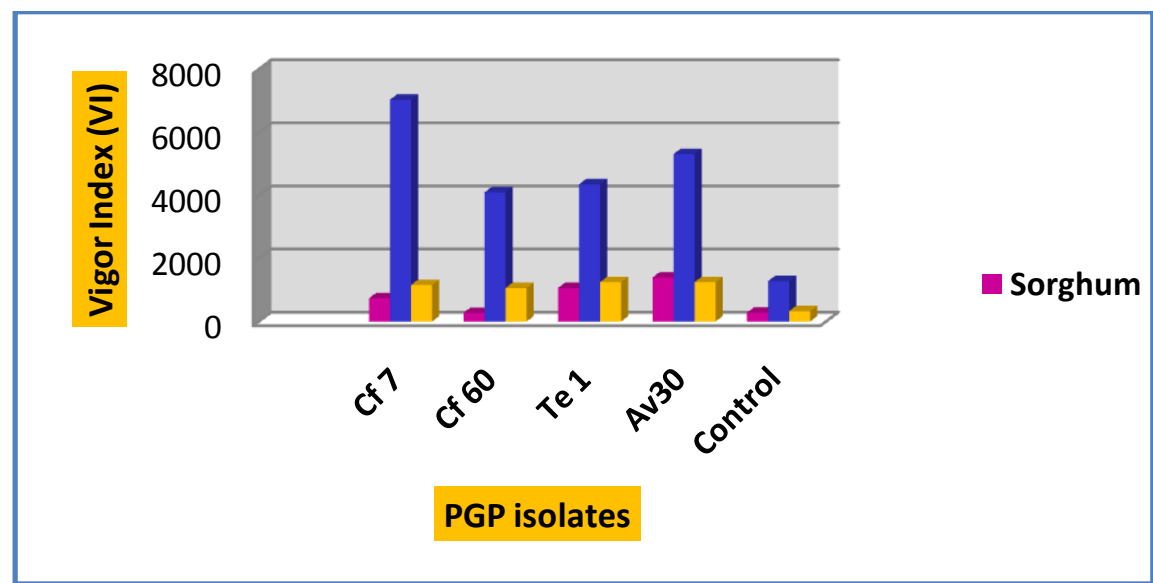

Fig. 2. Effect of PGPR isolates on vigor index of sorghum, maize and green gram seedlings

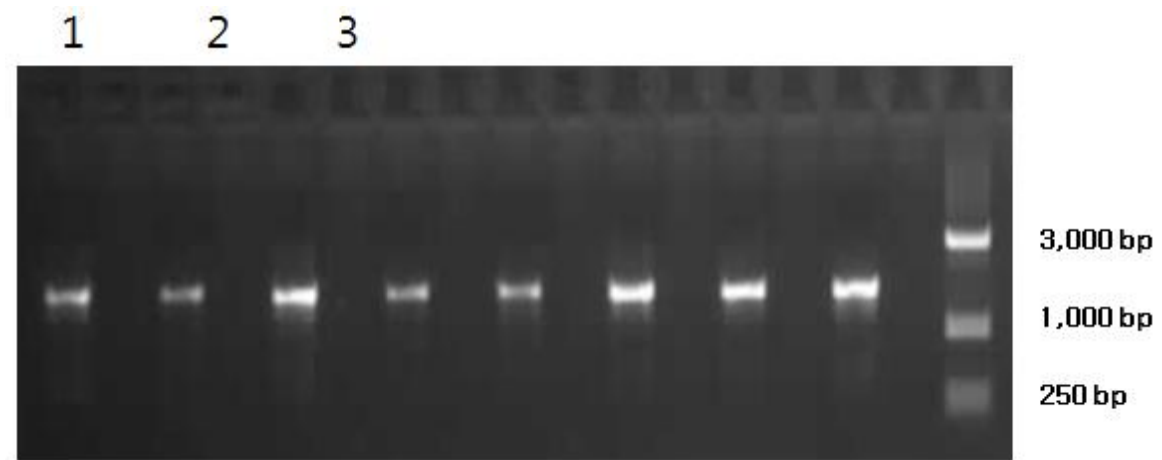

1 lane: Cf 7; 2 lane: Cf $60 ; 3$ lane: Te 1

Fig. 3. Gel electrophoresis of selected PGPR isolates 